\title{
International Contexts as Foundation for Enhancing Developmental Observational Skills Related to Intelligence Gathering
}

\author{
Jim Schnell* \\ Department of Division of Social \& Behavioral Sciences, Ohio Dominican University, USA
}

Submission: September 23, 2017; Published: October 12, 2017

*Corresponding author: Jim Schnell, Department of Division of Social \& Behavioral Sciences, Ohio Dominican University, Columbus, Ohio, 1216 Sunbury Road, Columbus, Ohio 43219, USA, Email: schnellj@ohiodominican.edu

\begin{abstract}
International contexts provide ripe foundation for practicing observational skills that correlate with skills involved in intelligence gathering. There are a wide variety of residential youth camp programs in the U.S. The diversity of such programs often reflects the cultural diversity of the campers attending. Awareness of cross-cultural communication issues is helpful to the camp environment as it sensitizes campers to the plight of the other person who is not from the various sub-groupings the camper belongs to. It perpetuates acceptance of others. In this context crosscultural communication includes emphasis on the various cultures within the U.S., not just when dealing with international cultures.

Each camper and camp counselor has a varied background regarding race, ethnicity, class and socio-economic background. These divisions can be significant in U.S. society but such divisions can be minimized in a camp setting, primarily due to the shared space. Sharing time and space with a person that is "different" than yourself exposes us to the reality that we are not really that different. Many of our differences evolve from socially imposed barriers. It can be a profound experience to come to this realization at camp and then equally profound to leave camp and see the cultural barriers reconstructed
\end{abstract}

\section{Cross-Cultural Communication Defined}

As interaction among people from different cultural backgrounds increases so will the need for improved crosscultural understanding. World trade, educational opportunities, and the relative ease of travel have created an unprecedented situation in the world whereby cross-cultural encounters are becoming more common. Participants in these cross-cultural encounters use their own distinctive communicative styles, based on their cultural backgrounds, and problems can easily arise when the communicative styles differ. Cross-Cultural Communication occurs when we interact with someone from a different cultural background. Sometimes the differences between cultures is minimal and interaction is relatively unhindered (i.e. interaction between citizens of America and England). Other times the differences between cultures are significant and there are many obstacles in the way of common understanding. Such obstacles include language differences, conceptual barriers and varied communication norms [1].

\section{Cross-Sub cultural Communication}

Cross-cultural communication occurs when we interact with someone from a different cultural background. Cross-sub cultural communication occurs when we interact with someone from a different sub cultural background (i.e. a Euro-American farmer from Kansas interacting with an African-American merchant in Philadelphia). Cultures are comprised of a variety of subcultures that are geographical, economical, occupational, racial, and ethnic. In the U.S., for instance, we have subcultures grounded in different regions of the country (i.e. the Southerner), economic levels (lower, middle \& upper class), occupational (blue collar \& white collar), racial (based on physical features) and ethnic (based on cultural practices) [2].

Cross-sub cultural communication can be, at times, more difficult than cross-cultural communication. For instance, the author (as a European-American middle-aged professor in the social sciences) can interact more clearly with an Australian middle-aged professor in the social sciences, than the author can with a Vietnamese fisherman from New Orleans whose primary language is Vietnamese and who speaks very little English. This phenomenon is especially true in the United States because of the many groups that comprise the American culture. Cross-sub cultural communication is best remembered as a form of cross- 
cultural communication since the dynamics and problems are the same.

\section{Three Cultural Perspectives}

As we come to understand cross-cultural communication we need to consider the importance of culture as a foundation for our perspectives, for it is from our perspectives that we communicate. There are three primary cultural perspectives that define culture and affect communication norms within each culture: status differential, group orientation and contextual emphasis. These dimensions can be described with a continuum scale featuring the two extremes existing within each dimension.

\section{Contextual emphasis}

The author has found awareness of this dimension to be most beneficial in his cross-cultural encounters. The continuum scale for this dimension places high contextual emphasis at one end and low contextual emphasis on the other end. Communicators from low contextual emphasis cultures tend to convey meanings directly and verbally. One does not need to be very sensitive to understand what a low context communicator is trying to convey. If a low context communicator wants to borrow $\$ 15$. to buy lunch she'll say "Can I borrow $\$ 15$. for lunch? I'll pay you tomorrow". The U.S. is a low context culture.

Communicators from high contextual emphasis cultures tend to convey meanings indirectly and in nonverbal channels, as well as verbal channels. Much of the message is conveyed in how the message is presented rather than in what is said. Gesture is especially meaningful. Understanding the context or backdrop of the message is important. If a high context communicator wants to borrow $\$ 15$. to buy lunch she might say “I haven't eaten in 24 hours. Silly me, to make matters worse I forgot my lunch money today. Though I am hungry, the uncomfortable hunger pains will teach me not to forget my lunch money in the future. It is a good lesson for me to learn". This being said while she holds her stomach in an obvious gesture conveying hunger. This exaggerated example illustrates the point of how one can convey a request without explicitly stating it. China is a high contextual emphasis culture [3].

Cross-cultural communication problems can obviously occur when a high contextual emphasis communicator interacts with a low contextual emphasis communicator. Most striking is that the low contextual emphasis communicator could understandably miss high contextual emphasis messages being presented because she is not sensitive to high contextual emphasis messaging (i.e. nonverbal gestures and indirect verbal expressions). Thus, in cross-cultural encounters, it is helpful to consider the role contextual emphasis plays in the other interactants communication styles. Low Contextual Emphasis High Contextual Emphasis, Communicator Style-Communicator Style

\section{Group orientation}

The dimension of group orientation varies in each culture. The continuum scale extends from individualist (oriented toward the individual) on one end and group oriented (oriented toward the group) on the other end. Individualist countries, such as the U.S., place considerable importance on individual effort and freedoms. Our economic system rewards the individual who can compete in business and win against others.

Individualists are more to the point and don't mind arguing. Group oriented countries value the group and subordinate the individual to the group. Harmony and getting along with others is important in group oriented cultures. When the author first taught in China (a group oriented culture) he observed how his students commented on his "odd habit" of taking daily walks "alone". They tended to function in groups. The Chinese have a saying "It is the nail that stands high and alone that is first to be pounded". Individualist-Group Oriented

\section{Status differential}

This dimension deals with how a culture distributes status and how this distribution affects communication. All cultures can be placed on the high-status-distance-low-status-distance continuum scale. Cultures that rank high on the scale (as highstatus-distance cultures) will maintain significant separation among social classes and social classes will differ regarding communicative norms. For instance, the lower classes will be expected to show deference to the higher classes. The United States is nearer the low-status-distance position. As such, the American culture leans more toward equality among classes. We have class distinctions but they are not as strong as found in some other countries. This equality is expressed in our form of government (i.e. one person-one vote, equal opportunity provisions in the workplace and equal rights).

\section{High-Status-Distance-Low-Status-Distance}

The journey through life presents many lessons that are true for all people in all lands. One such lesson is that the journey through life, and especially those we share it with, are more important than the final destination.

It is those we share our idle moments with, those who know our dispositions (and help mold our dispositions), that we develop and share common attitudes, beliefs, and perspectives with. The key ingredient in this evolution is time [4].

\section{Time}

During work, play and relaxation. Minutes turn into days, turn into weeks, turn into months, turn into years, turn into lifetimes. Was it yesterday or last year? Does it matter? The times spent together, be they special, routine or mundane, create a common memory. 


\section{Memory}

Individual memories that draw from shared experiences create a collective memory. This collective memory is reinforced by, and in turn reinforces, what we do, how we do it, when we do it, and why we do it. Sociologists call these considerations "norms". Norms are like building blocks for the social order or culture. When an individual chooses to maintain, by choice or necessity, membership with the group (be it family, gang, church, sports team, social club, classroom or other organization)this is a statement of identity.

\section{Identity}

Is who we are and what we believe. It is the yardstick by which we measure our actions. Identity allows us to celebrate the blessings of life (and to handle the problems of life). Individual identity is comprised of the collective identities we share as members of various groups. This helps to make each person uniquely different which, in turn, seasons the various groups we belong to. Identity touches our first thought in the morning and our last thought at night. It answers the question "What do I want to do today?" It answers the question "What do I want to do with my life?" It answers the question "Who am I?" [5].

\section{Three Levels of Culture Shock}

As international travel becomes more common there is an increased awareness of phenomena associated with cross-cultural experiences. One such occurrence is culture shock. Culture shock is the anxiety experienced when one is confronted by unfamiliar cultural practices that are perceived to be frustrating. There are three levels of culture shock: Orientation/Elation, Frustration and Resolution. Not all individuals will necessarily experience all three levels but this sequential process is common.

\section{Orientation/Elation level}

During this period the individual is excited at being in the new environment. Feelings of optimism promote perceptual accentuation of positive aspects related to the new culture and minimal acknowledgement of possible problem areas. This level can last for a varied length of time depending upon the individual and the circumstances of her travel [6].

\section{Frustration level}

This level typically occurs when the traveler encounters situations perceived to be frustrating and confusing. What was initially novel now becomes annoying. Unfamiliar norms, customs, language and behavior combine to make the traveler, at times, mildly hostile toward the environment and the natives. A common reaction in this level is to withdraw from the culture as much as possible by spending more time with fellow travelers, who may be having similar experiences, or isolating yourself in your living quarters (perhaps furnished with familiar artifacts from your home culture). At times a depression can set in that is so strong the traveler must return to her home country.

\section{Resolution level}

The resolution level begins as the traveler grows out of the frustration level. She has developed coping mechanisms for existing in the new culture and begins to develop a balanced perspective regarding positive and negative aspects of the new culture. Much of this resolution level is based on enhanced familiarity with the new culture. At this point the traveler feels comfortable in the new culture and has no problem functioning through daily activities (i.e. knowing how to mail a letter, prepare food, procure transportation and make necessary purchases). The traveler has adjusted to the new surroundings [7].

During the author's travels to foreign (to him) cultures he can tell he has progressed to the resolution level when he has enough objectivity to recognize a fellow traveler who is in the frustration level and that he is able to help her through that period. To illustrate these three levels of culture shock the author will briefly describe culture shock he experienced in China during his first visit. Orientation/Elation Level - He arrived in Beijing and was elated to be there. He had read a lot about China and to see what he had read about, especially since China had been closed to the outside world for the most part, was exciting. Students were eager to learn and had good study habits.

Frustration Level during his fourth week there, some graduate students in his graduate seminar turned in papers that were blatantly plagiarized. Plagiarism in the U.S. is a serious matter, a student can be expelled for plagiarism, and he feared if he reported the plagiarism the students would be expelled and punished (since China tends to be more strict in matters where the individual has committed wrongdoing). He felt his turning them in could negatively affect the course of their lives and jeopardize all they had worked for. It was a frustrating period of reflection that produced anxiety for him and hostility, from his view, toward the situation.

Resolution Level the author finally confided the plagiarism issue to a trusted staff member and he told the author "Oh yes, I've heard Americans don't like that practice. It is no big deal here". The staff member went on to explain that students will sometimes borrow the work of an author, much as is done in the U.S., but not footnote the borrowing as is done in the U.S. The author thought about it for awhile and realized Americans are firm believers in individualism and individual ownership of intellectual property whereas China is more collectivist and basically believes ideas "belong to the masses". Thus, not citing an idea as belonging to somebody else would not be a big deal. The author accepted that, since he was in their country, he would have to be tolerant of this practice and, at the same time, he could share his opinion on the matter with students. When the author discussed the matter with students he explained this type of plagiarism, in the U.S., could result in expulsion from schools. They were very surprised. 
Over time he became more tolerant because he could see they were very bright and he figured their educational system, though it appeared flawed in some areas to him, must be effective overall to be able to produce intelligent students such as they (and others) were. He adjusted to the situation by explaining if they ever came to the U.S. to study, they must not plagiarize in their papers and that they must always footnote the work of others. He stated since he was in China he would adapt to their practice but if they came to the U.S. they must adapt to American practices [8].

They concurred and he can add, when some of them did eventually come to the U.S., they did adapt to American approaches. Culture shock is normally associated with leaving a home culture and traveling to a distant land. However, you can experience culture shock without even leaving your own country. You merely need to suffer the anxiety experienced when one is confronted by unfamiliar cultural practices that are perceived to be frustrating. This can happen in cross-sub cultural communication and when interacting with foreigners in your home culture. Keep in mind, experiencing culture shock in cross-sub cultural communication and when interacting with foreigners in your own culture, is not very common. It is the exception rather than the rule, but it does happen.

Culture shock in cross-sub cultural communication occurs within the same framework as culture shock in cross-cultural communication except the interactants are from different subcultures (but of the same culture) instead of being from different cultures. For example, as a college freshman the author had the opportunity to study at a college in Florida and spend time in Miami. He was intrigued with the Little Havana section of Miami and enjoyed experiencing the Cuban-American subculture. He was surprised to see how widely Spanish was spoken, even though he was in the U.S. Such diversity was new to the author since he was born, raised and attending a university in central Ohio. He experienced a degree of hostility when he decided to patronize a Cuban-American barbershop.

He had difficulty communicating with the barber because his barber couldn't speak English very good. The author's intended message was "I just need a trim". The message the barber perceived was "Cut all my hair off. Half his head had a burr style haircut before the author realized what was happening. He ended up with a burr haircut overall and wasn't happy about it. Resolution occurred for when he appreciated the humor surrounding the situation, especially since hair grows back. During return visits to the Little Havana area the author was careful to ensure accuracy before assuming understanding. It was good training for his future travels out of the country. An individual can also experience culture shock in her own country when interacting with people from other cultures. The key ingredient is interaction between individuals who are culturally different. The author experienced such a type of culture shock while serving in the U.S. Air Force.
The year was 1978, before the Iranian revolution, and the U.S. was still providing military training for Iranians. The author was training at an Air Force base in the U.S. and trained and lived with a group of Iranians. Though he had his own room he shared a common kitchen, living room and bathroom with Iranians (he was the lone American in his unit). The author didn't know much about Iran but, in the early period, he experienced orientation/ elation while learning about their culture, lifestyle and language. They were very friendly and interesting people.

Everything was fine until he entered the bathroom early one morning and found a skinned animal (about the size of a German shepherd dog) hanging in the bathtub. It had been gutted and blood was dripping down the drain in the bathtub. His motivation to bathe in the tub became absent. The smell was barely tolerable. It was the beginning of a Iranian religious holiday and during the next few days our living area experienced, by his standards, disruptive behavior (i.e. Iranian music played at odd hours, unusual eating hours, and types of singing and chanting). The gutted animal had been procured for consumption in accordance with traditional custom. After two days of this "holiday" he sought to move into a living unit that was occupied by Americans but his request was rejected. He decided to function as best he could.

The author never did gain an appreciation for their custom but he did enter his resolution when, about four days after it began, the holiday period abruptly ended and life returned to normal (as it had been prior to the holiday). The bathroom was clean (no gutted animals hanging around anyway), the kitchen was usable, and normal sleeping/quiet hours were observed. They tried to explain their cultural/religious holidays and, though the author didn't fully understand their explanations, he became aware that such holidays would occur from time to time. Whenever one started he merely asked "How long will this holiday last?" and practiced tolerance during that time frame. All in all it was an interesting learning experience.

It is helpful to remember there is variance with these culture shock levels. That is, there is no definite time period for each level and there can be overlap among levels. In some situations one or more of the levels can be unusually long and elaborate. The main point is if you can remember the culture shock phenomenon, and recognize it when you experience degrees of culture shock, this can help you deal with the situation and even learn about yourself in the process. When you experience culture shock related frustrations, the author has found being able to analyze them as such helps him keep a cool head and get through the situations.

\section{Application Summary}

Growth with cross-cultural communication skills needs to start with individual. Cross-cultural sensitivity cannot be taught. There needs to be a sincere belief by the individual that we live in a culturally diverse society, the camp setting can be reflective 
of that larger society and part of being a functioning member of the camp (and society overall) is daily functioning that accommodates diversity. Each person will do this in her own way. There is no "one size fits all" approach. The enlightenment that can come from this line of thinking will not happen automatically.

There can be challenges. One such challenge has to do with the culture shock that can occur. Functioning with individuals who are culturally different can be difficult when you are trying to negotiate shared meanings and approaches for varies issues that come up in shared living situations. It can initially be elating for a camper to be free of her parents and get unpacked at camp in a cabin full of campers her age and then go about the business of getting settled in. However, that first morning can present frustrations when it is raining and she sees one of her cabin mates wearing her favorite shirt at breakfast (without having asked her permission) because, from the other girl's background, it is okay to borrow such things without asking.

Resolution will typically occur when the campers involved in such scenarios learn to resolve these differences. From these challenges shared bonds can evolve. Thus, cabins can expect to go through the form, storm and norm process. Learning to interact with the different subcultures can be an excellent framework for learning to interact with different world cultures. The differences in the former situation have direct parallels with the differences in the latter situation. The ultimate lesson seems to reinforce an awareness that humans may differ in cultural outlook and practice but we have much in common as well.

Camp is a wonderful environment for reinforcing this awareness. It is a 24 hour a day experience that confronts each person in unique ways. There can be frustrations but overall such frustrations are part of a valuable learning experience. The first African-American the author met was at camp. The first Jewish person he met was at camp. It was an excellent way to get off on the right foot about learning how to interact with people who are culturally different. The frustrations that can occur are shared frustrations. These shared frustrations often go hand in hand with shared resolutions and, overall, they become shared experiences that grow into foundations for meaningful friendships.

\section{References}

1. Davis RP (1969) Church Camping. Nashville. Knox Publishing, Tennessee, USA.

2. Ensign J, Ensign R (1958) Camping Together as Christians. Nashville, Knox Publishing, Tennessee, USA.

3. Genne E, Genne W (1979) Church Family Camping and Conferences. Minneapolis, Judson Press, Minnesota, USA.

4. MacKay J (1966) Creative Counseling for Christian Camps. Omaha: Scripture Publishing, Nebraska, USA.

5. Purchase R, Purchase B (1972) Let's Go Outdoors With Children. Boston. Westminster Press, Massachusetts, USA.

6. Schnell James A, Kum Ba Yah (2014) A Song in the Air: An Analysis of a Spiritual Consciousness Raising Group After 50 Years of Group Camping. Munich, Germany, Europe.

7. Schnell JA (2009) The Camp Counselor's Guide to Interpersonal Communication. Monterey: American Camp Association, California, USA.

8. Springer JC (1971) Boys, Girls and God. Vantage Press, Pittsburgh, Pennsylvania, USA.

\section{Your next submission with Juniper Publishers will reach you the below assets}

- Quality Editorial service

- Swift Peer Review

- Reprints availability

- E-prints Service

- Manuscript Podcast for convenient understanding

- Global attainment for your research

- Manuscript accessibility in different formats

( Pdf, E-pub, Full Text, Audio)

- Unceasing customer service

Track the below URL for one-step submission https://juniperpublishers.com/online-submission.php 